\title{
Macrophage-derived foam cells impair endothelial barrier function by inducing endothelial-mesenchymal transition via CCL-4
}

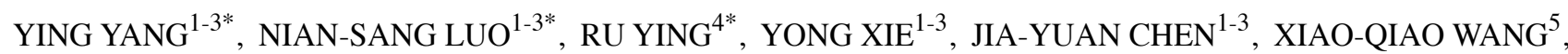 \\ ZHEN-JIE GU ${ }^{1-3}$, JING-TING MAI ${ }^{1-3}$, WEN-HAO LIU ${ }^{1-3}$, MAO-XIONG WU ${ }^{1-3}$, ZHI-TENG CHEN $^{1-3}$, \\ YONG-BIAO FANG ${ }^{1-3}$, HAI-FENG ZHANG ${ }^{1-3}$, ZHI-YI ZUO $^{3,6}$, JING-FENG WANG ${ }^{1-3}$ and YANG-XIN CHEN ${ }^{1-3}$ \\ ${ }^{1}$ Department of Cardiology, Sun Yat-sen Memorial Hospital of Sun Yat-sen University; \\ ${ }^{2}$ Guangdong Province Key Laboratory of Arrhythmia and Electrophysiology; ${ }^{3}$ Laboratory of RNA \\ and Major Disease of Heart and Brain, Sun Yat-sen Memorial Hospital of Sun Yat-sen University, Guangzhou, \\ Guangdong 510120; ${ }^{4}$ Department of Cardiology, The First Affiliated Hospital of Nanchang University, \\ Nanchang, Jiangxi 330006; ${ }^{5}$ Department of Anesthesiology, The Second Affiliated Hospital of \\ Guangzhou Medical University, Guangzhou, Guangdong 510120, P.R. China; \\ ${ }^{6}$ Department of Anesthesiology, University of Virginia, Charlottesville, VA 22908, USA
}

Received November 8, 2016; Accepted June 6, 2017

DOI: $10.3892 /$ ijmm.2017.3034

\begin{abstract}
Recently, endothelial-mesenchymal transition (EndMT) has been demonstrated to play an important role in the development of atherosclerosis, the molecular mechanisms of which remain unclear. In the present study, scanning electron microscopy directly revealed a widened endothelial space and immunohistofluorescence demonstrated that EndMT was increased in human aorta atherosclerotic plaques. M1 macrophage-derived foam cell (M1-FC) supernatants, but not M2 macrophage-derived foam cell (M2-FC) supernatants, induced EndMT. A protein array and enzymelinked immunosorbent assay identified that the levels of several cytokines, including C-C motif chemokine ligand 4 (CCL-4) were increased in M1-FC supernatants, in which EndMT was promoted, accompanied by increased endothelial permeability and monocyte adhesion. Furthermore, anti-CCL-4 antibody abolished the effects of M1-FC supernatants on EndMT. At the same time, CCL-4 activated its receptor, C-C motif chemokine receptor-5 (CCR-5), and upregulated transforming growth
\end{abstract}

Correspondence to: Dr Jing-Feng Wang or Dr Yang-Xin Chen, Department of Cardiology, Sun Yat-sen Memorial Hospital of Sun Yat-sen University, 107 Yanjiang West Road, Guangzhou, Guangdong 510120, P.R. China

E-mail: dr_wjf@hotmail.com

E-mail: tjcyx1995@163.com

*Contributed equally

Key words: macrophage, foam cells, endothelial-mesenchymal transition, $\mathrm{C}-\mathrm{C}$ motif chemokine ligand 4 , atherosclerosis factor- $\beta$ (TGF- $\beta$ ) expression. Further experiments revealed that EndMT induced by CCL-4 was reversed by treatment with CCR-5 antagonist and the RNA-mediated knockdown of TGF- $\beta$. On the whole, the data of the present study suggest that M1-FCs induce EndMT by upregulating CCL-4, and increase endothelial permeability and monocyte adhesion. These data may help to elucidate the important role of EndMT in the development of atherosclerosis.

\section{Introduction}

Atherosclerosis is the predominant cause of coronary artery disease and stroke, and thus, is the leading cause of mortality and disability, globally (1). However, the precise molecular mechanisms involved in the initiation and progression of atherosclerosis remain poorly defined. Vascular integrity is critical for cardiovascular homeostasis, and endothelial barrier dysfunction leads to the leakage and retention of low-density lipoprotein (LDL), the extravasation of monocytes into the vassal wall and the decrement of cholesterol efflux capacity, which triggers the formation of atherosclerotic plaques (2-5).

Endothelial cell integrity is crucial for maintaining lesionfree arteries. Recent evidence has indicated that endothelial cells retain various degrees of plasticity. Endothelial cells can achieve a mesenchymal phenotype through endothelialmesenchymal transition (EndMT) (6). EndMT is characterized by the loss of specific endothelial cell marker expression, including vascular endothelial cadherin (VE-cadherin) and platelet endothelial cell adhesion molecule-1 (PECAM-1; also known as CD31), and the increased expression of mesenchymal cell marker, including $\alpha$-smooth muscle actin ( $\alpha$-SMA) and vimentin. During EndMT, endothelial cells lose cell polarity and cell-cell adhesion. They then detach from the organized endothelial layer, and then migrate towards the surrounding 
tissue, which damages endothelial junction stability and increases vascular permeability $(7,8)$. EndMT plays an important role in various pathological conditions, including cardiac and nephritic fibrosis $(6,9)$, pulmonary hypertension $(10,11)$, vascular calcification (12), endocardial fibroelastosis (13) and most importantly, atherosclerosis (14-17). Recently, using an endothelial cell fate mapping technique, EndMT was demonstrated to participate in the process of atherosclerosis by increasing the deposition of fibronectin and adhesion molecules (16). Additionally, EndMT-derived fibroblast-like cells have previously been shown to contribute to atherosclerotic plaque progression and destabilize atherosclerotic lesions by altering the collagen-matrix metalloproteinase balance (17).

In contrast to the consensus that EndMT promotes atherosclerosis, the cause of EndMT during this pathological process is largely unknown. In atherosclerotic lesions, monocytes infiltrate into the subendothelium, differentiate into macrophages, internalize modified lipids and then become foam cells (18-20). Macrophages and foam cells secrete inflammatory cytokines and chemokines, which induces a non-resolving inflammatory process and affects plaque development $(21,22)$. Emerging evidence has indicated that macrophages are comprised of heterogeneous cell populations, which is determined by the surrounding microenvironment and that they can switch from one phenotype to another (23-25). Classically activated M1 macrophages produce tumor necrosis factor (TNF), interleukin (IL)-6 and IL-1 $\beta$, exacerbating the inflammatory response and promoting the development of atherosclerotic lesions (26). By contrast, alternatively activated M2 macrophages are an anti-inflammatory phenotype and have been reported to be protective in atherosclerosis $(27,28)$. However, despite the central role of macrophages and foam cells in the development of atherosclerosis, their function in the process of EndMT has yet to be determined. Thus, in the present study, we investigated the importance of different phenotypic macrophages and foam cells in EndMT during atherosclerosis and explored the underlying mechanisms.

\section{Materials and methods}

Cell culture. Human aortic endothelial cells (HAECs; ATCC ${ }^{\circledR}$ PCS-100-011 ${ }^{\mathrm{TM}}$ ) were purchased from American Tissue Type Culture Collection (Manassas, VA, USA) and cultured in EGM-2 BullerKit ${ }^{\mathrm{TM}}$ Medium (cat. no. 3162; Lonza, Walkersville, MD, USA). The cells were incubated in a humidified atmosphere containing $5 \% \mathrm{CO}_{2}$ at $37^{\circ} \mathrm{C}$ and passaged every 4 days (split ratio, $1: 3$ ) using $0.25 \%$ trypsin. The cells were used between passages 2 and 7 .

Macrophages were induced as previously described $(29,30)$. Briefly, peripheral blood mononuclear cells were isolated, as previously described (31). Peripheral blood mononuclear cells (PBMCs) were isolated from the peripheral blood of 106 healthy volunteers. This study was part of the project 'Macrophage derived foam cells impair endothelial barrier function by inducing endothelial mesenchymal transition'. All the study protocols were approved by the Clinical Ethics Committees of Sun Yat-sen Memorial Hospital of Sun Yat-sen University. All blood samples and procedures were approved by the Clinical Ethics Committees of Sun Yat-sen Memorial Hospital of Sun Yat-sen University. Briefly, peripheral blood $(20 \mathrm{ml})$ was drawn into heparinized tubes from the 106 healthy volunteers. Blood was diluted with PBS at 1:1, and then overlaid on lymphocyte separation medium (cat. no. 0850494; MP Biomedicals, LLC, Santa Ana, CA, USA; density at $20^{\circ} \mathrm{C}: 1.0770-1.0800 \mathrm{~g} / \mathrm{ml}$ ), centrifuged at 2,300 rpm for $30 \mathrm{~min}$, and progressively slowed down for the last $6 \mathrm{~min}$. PBMCs were collected and washed twice in PBS at 2,000 rpm for $5 \mathrm{~min}$. Monocytes were positively selected from PBMCs using CD14 microbeads (cat. no. 130-050201; Miltenyi Biotec, Auburn, CA, USA), and subsequently cultured in RPMI-1640 medium supplemented with $10 \%$ fetal bovine serum (FBS; Gibco; Thermo Fisher Scientific, Inc., Waltham, MA, USA) at a density of $1 \times 10^{6}$ cells $/ 10 \mathrm{~cm}^{2}$. To induce M1 polarization, the cells were incubated in the presence of $100 \mathrm{ng} / \mathrm{ml}$ granulocyte-macrophage colony-stimulating factor (GM-CSF; PeproTech, Inc., Rocky Hills, NJ, USA) for 7 days, and then treated with $100 \mathrm{ng} / \mathrm{ml}$ lipopolysaccharide (eBioscience, San Diego, CA, USA) and $20 \mathrm{ng} / \mathrm{ml}$ interferon- $\gamma$ (PeproTech, Inc.) for $24 \mathrm{~h}$. To achieve M2a and M2c polarization, the cells were incubated in the presence of $100 \mathrm{ng} / \mathrm{ml}$ macrophage colony-stimulating factor (M-CSF; PeproTech, Inc.) for 7 days, and then treated with $20 \mathrm{ng} / \mathrm{ml}$ IL-4 or $20 \mathrm{ng} / \mathrm{ml}$ IL-10 (PeproTech, Inc.) for $24 \mathrm{~h}$. Following polarization, the cells were stimulated with $100 \mu \mathrm{g} / \mathrm{ml}$ oxidized LDL (ox-LDL; Yiyuan Biotechnology, Guangzhou, China) for $12 \mathrm{~h}$ to induce differentiation into foam cells. Subsequently, the culture media were collected and centrifuged at $2,000 \mathrm{x} \mathrm{g}$ for $30 \mathrm{~min}$ at $4^{\circ} \mathrm{C}$ to remove the debris and frozen at $-80^{\circ} \mathrm{C}$.

HAECs were seeded at $60-70 \%$ confluency in 6-well plates, and starved in EBM-2 (cat. no. 3156; Lonza) without FBS for $18 \mathrm{~h}$. The HAECs were then treated with conditioned medium from different phenotypic macrophages or foam cells at a 1:1 ratio with EBM-2 for 6 days. The medium was changed every other day.

Following serum starvation, the HAECs were treated with CCL-2 $(0,12.5,25$ and $50 \mathrm{ng} / \mathrm{ml})$, CCL-3 (0, 25, 50 and $100 \mathrm{ng} / \mathrm{ml}), \mathrm{CCL}-4$ (0, 25, 50 and $100 \mathrm{ng} / \mathrm{ml}), \mathrm{CCL}-5$ (0, 10, 20 and $40 \mathrm{ng} / \mathrm{ml})$ and CCL-7 $(0,25,50$ and $100 \mathrm{ng} / \mathrm{ml})$ for 6 days, respectively. HAECs were also treated with CCL-2 $(50 \mathrm{ng} / \mathrm{ml})$, CCL-3 (100 ng/ml), CCL-4 (100 ng/ml), CCL-5 (40 ng/ml) and CCL-7 (100 ng/ml) for 2, 4 and 6 days, respectively.

These recombinant human chemokines were obtained from PeproTech, Inc. as follows: CCL-2 (cat. no. 300-04), CCL-3 (cat. no. 300-08), CCL-4 (cat. no. 300-09), CCL-5 (cat. no. 300-06), CCL-7 (cat. no. 300-17).

The conditioned medium of the M1-FCs was pre-treated at $37^{\circ} \mathrm{C}$ with $10 \mu \mathrm{g} / \mathrm{ml}$ human CCL-4 neutralizing antibody (cat. no. ab9675; Abcam, Cambridge, MA, USA) or isotype IgG control (cat. no. ab37415; Abcam) for $1 \mathrm{~h}$. The processed conditioned media were then added to the HAECs at a 1:1 ratio with EBM-2. The HAECs were treated for 6 days, and the medium was changed every other day.

Following serum starvation, the HAECs were pre-treated with $5 \mu \mathrm{mol} / 1$ maraviroc (cat. no. S2003; Selleck Chemicals LLC, Houston, TX, USA) for $2 \mathrm{~h}$, prior to stimulation with $100 \mathrm{ng} / \mathrm{ml} \mathrm{CCL}-4.0 .1 \%$ (vol/vol) DMSO was used as a solvent control. HAECs were treated for 6 days, and the medium was changed every other day.

Adenovirus packaging and RNA knockdown. To investigate the underlying mechanisms of $\mathrm{C}-\mathrm{C}$ motif chemokine ligand-4 
(CCL-4)-induced EndMT in HAECs, transforming growth factor- $\beta$ (TGF- $\beta$ ) expression was knocked down in the HAECs using recombinant adenoviruses with the pAdEasy packaging system. Briefly, recombinant vectors carrying RNA interference sequences targeting TGF- $\beta$ were generated using plasmid pRNAT-H1.1/Adeno and incision enzymes MluI and HindIII (forward, 5'-CCAACGCGTGACTACTACGCCAA GGAttc aagagaTCCTTGGCGTAGTAGTCTTTTTAAGCTT GCG-3'; reverse, 5'-CCGAAGCTTAAAAAGACTACTACG CCAAGGA tctcttgaaTCCTTGGCGTAGTAGTCACGC GTCCG-3'). Cloned vectors were linearized by PmeI and subsequently transfected into BJ5183 bacteria (containing plasmid pAD-Easy-1) using electroporation for homologous recombination. The recombinant vector was linearized with $P a c I$ and amplified in AD293 cells (cat. no. FH0251; FuHeng Biology, Shanghai, China). The cells were then lysed and the adenovirus was purified by the cesium chloride $(\mathrm{CsCl})$ density gradient ultracentrifugation method and diluted in phosphatebuffered saline (PBS) as previously reported (32). Finally, the virals titer was determined using the cytopathic effect (CPE) counting method. The HAECs were infected with adenovirus at a concentration of $50 \mathrm{pfu} / \mathrm{cell}$.

Scanning electron microscopy. Human aortas were obtained from cadaver organ donors. We collected 1 normal and 2 atherosclerotic ascending aorta samples, judged by medical history and Oil Red O and H\&E staining of the aortic tissues. The clinical and demographic characteristics of the cadaver organ donors are shown in Table I. All the samples were obtained from cadaver organ donors, who died due to car accidents. The aortic tissues were obtained, at the same time with other donated organs, after the clinical announcement of brain death, with circulation stabilization, and also with signed organ donor documents, consent and the agreement of family members, and ethics committee approval. All procedures were approved by the Clinical Ethics Committee of Sun Yat-Sen Memorial Hospital of Sun Yat-Sen University (Guangzhou, China). For examination under a Hitachi S-3400N scanning electron microscope (serial no. 341117-08; Hitachi, Ltd., Tokyo, Japan), vessel sections were fixed in $2.5 \%$ glutaraldehyde in PBS overnight. After washing 3 times with PBS, the sections were dehydrated in a series of ethanol dilutions (30, 50, 70, 90 and 100\%), dried by the critical-point method, sputtered by gold-palladium and prepared for anlaysis using a Hitachi S-3400N scanning electron microscope (Hitachi, Ltd.).

Immunohistofluorescence. Briefly, the samples were incubated with rabbit anti-von Willebrand factor (vWF) polyclonal antibody (1:200; cat.no.ab6994) and mouse anti- $\alpha$-SMA monoclonal antibody (1:200; cat. no. ab18147) (both from Abcam) at $4^{\circ} \mathrm{C}$ overnight. After washing 3 times with PBS-Tween-20 (PBST), they were incubated with the appropriate Alexa Fluor 488 goat anti-rabbit or Alexa Fluor 594 goat anti-mouse antibody (Invitrogen; Thermo Fisher Scientific, Inc.) in 5\% bovine serum albumin (BSA) for $1 \mathrm{~h}$ at room temperature. The nuclei were stained using 4',6-diamidino-2-phenylindole (DAPI) $(1 \mu \mathrm{g} / \mathrm{ml}$; cat. no. D9542; Sigma-Aldrich; Merck Millipore, Darmstadt, Germany) for 3 min. EndMT was evaluated by the criteria described in a previous study (33). All counts were performed and compared by 2 investigators.
Table I. Selected clinical and demographic characteristics of the cadaver organ donors.

\begin{tabular}{lccc}
\hline Subject number & 1 & 2 & 3 \\
\hline Group & Normal & AS & AS \\
Age (years) & 53 & 54 & 49 \\
Gender & Male & Male & Female \\
Smoking & No & No & No \\
History of CAD & No & Yes & Yes \\
History of DM & No & No & No \\
History of hypertension & No & No & Yes \\
Oil Red O staining & Negative & Positive & Positive \\
H\&E staining & Normal & AS & AS \\
\hline
\end{tabular}

AS, atherosclerosis; CAD, coronary artery disease; DM, diabetes mellitus.

Western blot analysis. The cells were washed, lysed and total protein was extracted. The total protein concentration was determined using a BSA Protein Assay kit (Beyotime Biotechnology, Shanghai, China) according to the manufacturer's instructions and western blot analysis was performed. Briefly, protein extraction was separated by sodium dodecyl sulfate-polyacrylamide gel electrophoresis (SDS-PAGE) followed by transfer onto polyvinylidene fluoride membranes [cat. nos. IPVH00010 $(0.45 \mu \mathrm{m})$ and ISEQ00010 $(0.2 \mu \mathrm{m})$; EMD Millipore Corporation, Billerica, MA, USA]. The membrane was blocked in 5\% BSA for $1 \mathrm{~h}$ at room temperature and immunoblotted with the corresponding antibodies at $4^{\circ} \mathrm{C}$ overnight. Glyceraldehyde 3-phosphate dehydrogenase (GAPDH) was used as an internal control. The antibodies used are listed as follows: rabbit anti-CD31 polyclonal antibody (1:1,000; cat. no. ab28364; Abcam), goat anti-VE-cadherin polyclonal antibody (1:1,000; cat. no. sc-6458; Santa Cruz Biotechnology, Inc., Dallas, TX, USA), rabbit anti-vimentin monoclonal antibody (1:1,000; cat. no. 5741; Cell Signaling Technology, Inc., Danvers, MA, USA), rabbit anti- $\alpha$-SMA polyclonal antibody $(1: 1,000$; cat. no. ab5694), rabbit anti-fibroblast-specific protein-1 (FSP-1) polyclonal antibody (1:1,000; cat. no. ab27427) (both from Abcam), rabbit anti-GAPDH monoclonal antibody $(1: 1,000$, cat. no. 2118$)$, rabbit anti-TGF- $\beta$ polyclonal antibody $(1: 1,000$; cat. no. 3711) (both from Cell Signaling Technology, Inc.) and rabbit anti-vascular cell adhesion molecule-1 (VCAM-1) monoclonal antibody (1:1,000; cat. no. ab134047; Abcam). The membranes were washed 3 times with PBST and incubated with the following appropriate secondary HRP-linked antibodies: goat anti-rabbit IgG (1:5,000; cat. no. 7074; Cell Signaling Technology, Inc.) or donkey anti-goat IgG (1:5,000; cat. no. sc-2020; Santa Cruz Biotechnology, Inc.), for $1.5 \mathrm{~h}$ at room temperature. After washing, detection was performed using an advanced enhanced chemiluminescence system.

Cytokine and chemokine analysis. The TGF- $\beta 1$ level was measured in the culture supernatants of the macrophages treated with or without ox-LDL using a commercial enzyme linked immunosorbent assay (ELISA) kit (Neobioscience, Shenzhen, China). The levels of other cytokines and chemokines 

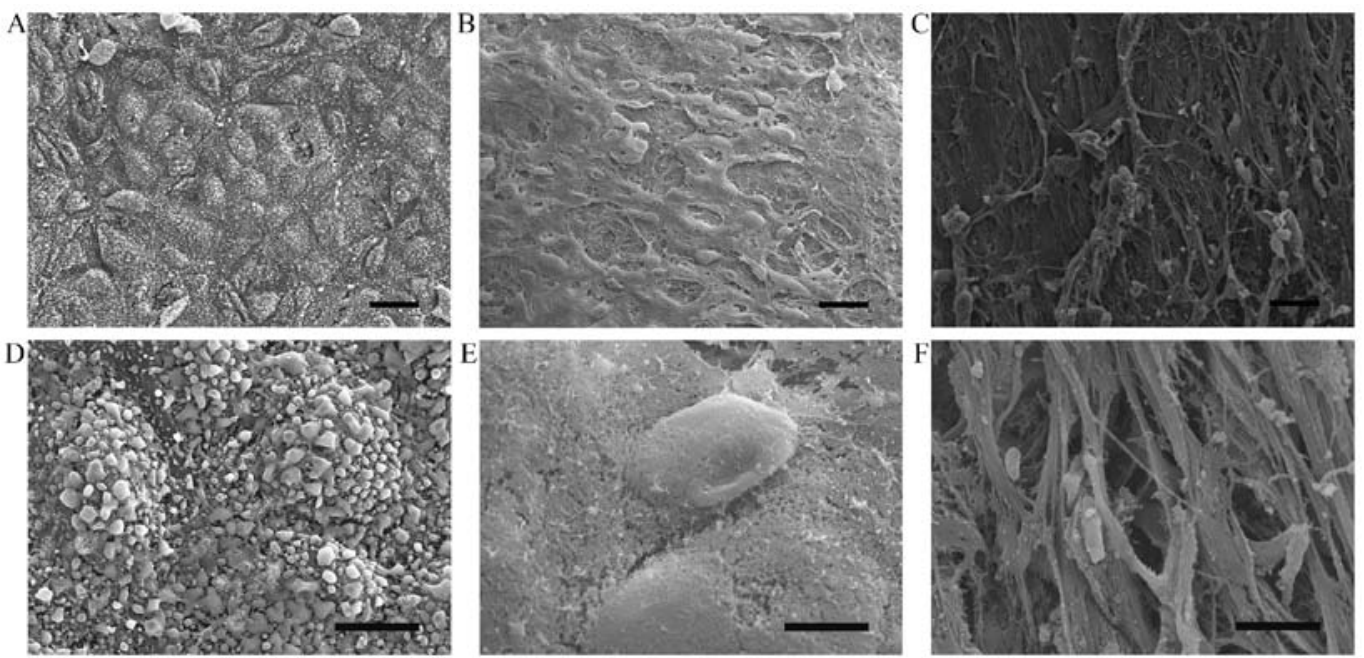

Figure 1. Morphological changes in normal human aorta and in atherosclerotic legions. (A and D) Scanning electron microscopic images of a normal aorta with the intact arrangement of endothelial cells. (B, C, E and F) Rough endothelial surface with exposed collagen matrix in atherosclerotic lesions. (A-C) Magnification, x300; scale bar, $20 \mu \mathrm{m}$. (D, E and F) x2, magnification, x500; scale bar, $2 \mu \mathrm{m}$.

[including IFN- $\gamma$, IL-1 $\beta$, TNF- $\alpha$, IL-12p70, IL-2, IL-4, IL-5, IL-6, GM-CSF, IL-18, Eotaxin, GRO- $\alpha$, IL-8, IP-10, MCP-1 (CCL-2), MIP-1 $\alpha$ (CCL-3), MIP-1 $\beta$ (CCL-4), SDF-1 $\alpha$, IL-13 and RANTES (CCL-5)] were measured using the ProcartaPlex ${ }^{\mathrm{TM}}$ Multiplex Immunoassay kit (cat. no. EPX200-12173-901; Affymetrix Inc., Santa Clara, CA, USA), according to the manufacturer's instructions.

The chemokine expression profiles of the M1 macrophages and M1-derived foam cells were assessed using a Human Chemokine array kit (cat. no. ARY017; R\&D Systems, Inc., Minneapolis, MN, USA), according to the manufacturer's instructions. Briefly, the arrays were incubated in the supernatants and detection antibody cocktail overnight at $4^{\circ} \mathrm{C}$. After washing, the arrays were incubated with streptavidin-horseradish peroxidase and then exposed to the Chemi Reagent Mix. The reaction intensity was analyzed using the G:BOX XT4 imager (Syngene, Frederick, MD, USA) and the optical density was calculated using ImageJ software.

Monocyte adhesion assay. THP-1 cells (Boster Biological Technology, Wuhan, China) were cultured in RPMI-1640 medium supplemented with $10 \%$ FBS and stained with $50 \mu \mathrm{M}$ calcein-AM for $30 \mathrm{~min}$ at $37^{\circ} \mathrm{C}$. The labeled THP-1 cells were seeded at a density of $5.0 \times 10^{5}$ cells $/ \mathrm{ml}$ on confluent HAECs, which were pre-treated with $100 \mathrm{ng} / \mathrm{ml} \mathrm{CCL}-4$ (PeproTech, Inc.) for 6 days. Following $1 \mathrm{~h}$ of incubation, non-adherent cells were removed by gentle washing with PBS and THP-1 cell adhesion was assessed using a Nikon Ti-S inverted fluorescence microscope (serial no. 533477; Nikon, Tokyo, Japan).

Endothelial monolayer permeability. The HAECs were cultured on $0.2 \%$ gelatin-coated $6.5 \mathrm{~mm}$-diameter Transwell inserts ( $0.4 \mu \mathrm{m}$ pore size; Corning Inc., Corning, NY, USA). Fluorescein isothiocyanate (FITC)-dextran $(1 \mathrm{mg} / \mathrm{ml}$; molecular weight, $70 \mathrm{kDa}$; Sigma-Aldrich; Merck Millipore) was added to the upper chamber. The medium from the lower chamber was collected after $1 \mathrm{~h}$ and fluorescence measured using a SpectraMax M5 microplate reader (Molecular
Devices, LLC, Sunnyvale, CA, USA; excitation, $485 \mathrm{~nm}$; emission, $525 \mathrm{~nm}$ ).

Statistical analysis. Data are presented as the means \pm standard error of mean. Results were analyzed by a two-tailed Student's t-test or one-way analysis of variance with Bonferroni post-hoc test for multiple comparisons as appropriate using GraphPad Prism software (GraphPad Software, Inc., La Jolla, CA, USA). A value of $\mathrm{P}<0.05$ was considered to indicate a statistically significant difference.

\section{Results}

Endothelial barrier dysfunction and EndMT occur in human atherosclerotic plaques. To demonstrate altered endothelial integrity in atherosclerotic plaques, human aorta specimens were subjected to scanning electron microscopy. The results demonstrated that endothelial cells in the normal control aorta tissue were arranged in an intact and regular manner (Fig. 1A and D) whereas endothelial cells were partially preserved with altered polarity, and the subendothelial surface with a fibrous cap was visible in the atherosclerotic lesions (Fig. 1B, C, E and F).

As EndMT is an important cause of the loss of endothelial cells polarity, the endothelial changes due to EndMT in atherosclerotic plaques were examined by immunohistofluorescence staining. As shown in Fig. 2, evidence of EndMT, as indicated by the co-localization of vWF and $\alpha$-SMA expression, was more pronounced in atherosclerotic lesions compared with the normal control tissue. These data suggest that EndMT may contribute to endothelial cell polarity changes and the development of atherosclerosis.

Conditioned medium from M1-FCs stimulates HAECs to undergo EndMT in vitro. The reason for EndMT and endothelial cell polarity loss in atherosclerotic plaques remains unclear. Macrophages and foam cells are the major cellular component of atherosclerotic plaques and, thus, their functions are ciritical in the atherosclerotic process. Therefore, the role of 

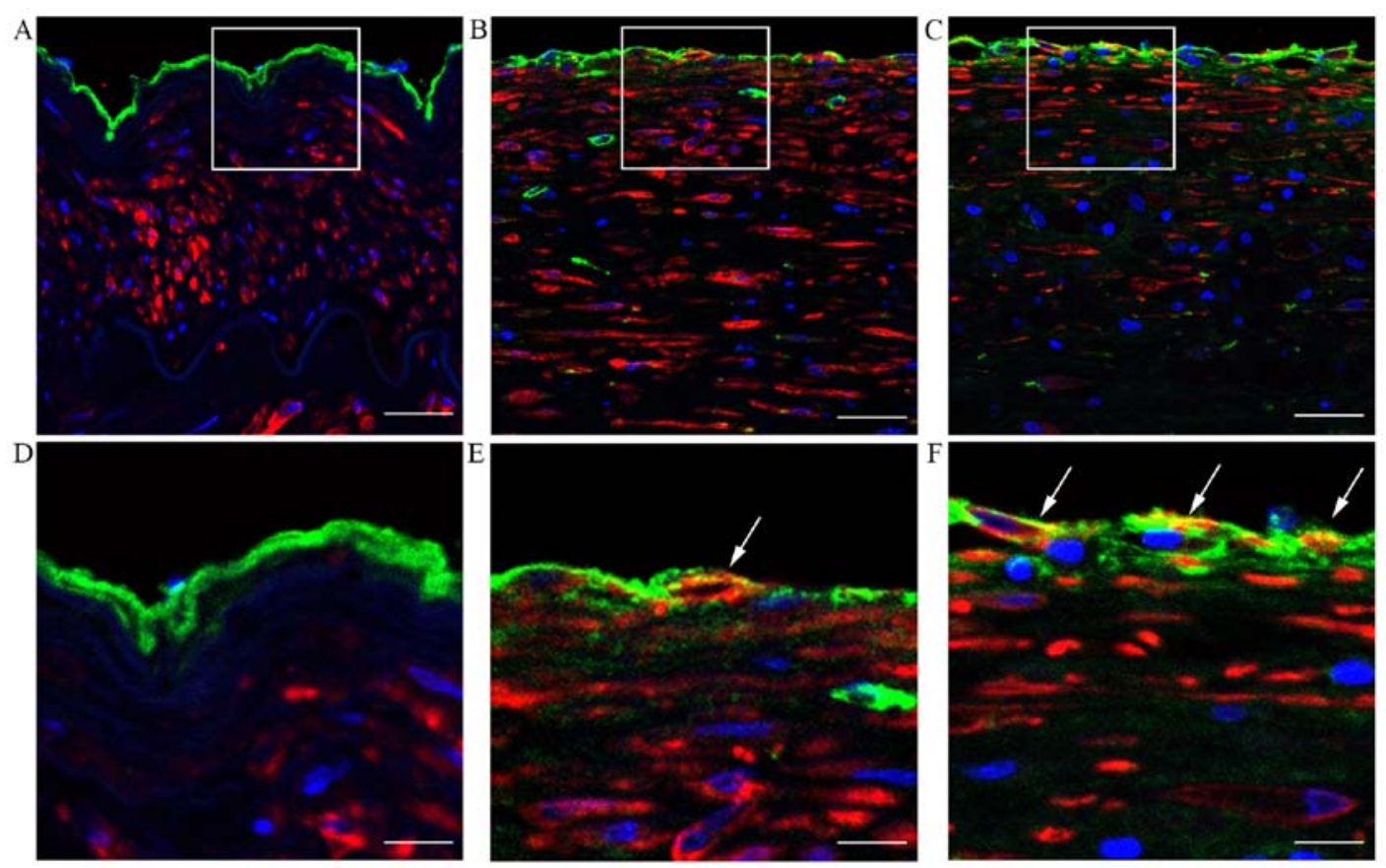

Figure 2. Endothelial mesenchymal transition in human aortic atherosclerotic plaques. Immunohistofluorescence staining showing human aortic tissues from (A and D) normal group and (B, C, E and F) patients with atherosclerosis. Sections were stained with von Willebrand factor antibody (green), $\alpha$-smooth muscle actin antibody (red) and DAPI (blue). Co-localization is indicated with white arrows. (A-C) Scale bar, $50 \mu \mathrm{m}$; (D, E and F) scale bar, $20 \mu \mathrm{m}$. The white boxes in panels A-C indicate the area of the enlarged image in panels D-F.

macrophages and foam cells during the changes of endothelial cells in plaques was investigated. Macrophages are classically divided into 2 groups, namely, M1 and M2 macrophages. Different phenotypes of macrophages have distinct properties. In this study, the effects of both subtypes on the endothelium were examined. It was observed that supernatants from M1 macrophage-derived foam cells (M1-FCs) induced EndMT, with the cell morphology changing from a cobblestone-like appearance to a spindle-shaped pattern (Fig. 3D), whereas, supernatants from M2a-FCs or M2c-FCs did not exhibit these changes (Fig. 3E and F). Notably, the macrophages (M1, M2a and M2c) not pre-treated with ox-LDL did not exert any EndMT-like effects on endothelial cells (Fig. 3A-C). Western blot analysis demonstrated that the expression of endothelial markers (VE-cadherin and CD31) was markedly reduced, together with an observable increase in the expression of mesenchymal markers ( $\alpha$-SMA and FSP-1) in the HAECs treated with conditioned medium from M1-FCs (Fig. 3G).

Levels of cytokines and chemokines in the supernatants. It is not clear which components in M1-FC conditioned medium induced EndMT. TGF- $\beta 1$ is one of the most important factors for both epithelial-mesenchymal transition (EMT) and EndMT, thus, TGF- $\beta 1$ levels were examined in the supernatants of macrophages and foam cells. The levels of TGF- $\beta 1$ were not significantly increased in the M1-FCs compared with the M1 macrophages (Fig. 4). In addition, as inflammatory cytokines result in EndMT, the levels of classical cytokines, including TNF- $\alpha$, IL-1 $\beta$ and IFN- $\gamma$, were measured. There was a significant difference in the levels of these cytokines in the conditioned medium of M1-FCs compared with those in M1 macrophages (Fig. 4). However, the concentration of these cytokines was too low to induce EndMT (16)
Secretion of CCL-4 from M1 macrophage-derived foam cells is involved in EndMT. Chemokines are important inducers of EMT, and are critical in the formation and progression of atherosclerosis plaques (34-37); thus, a human chemokine protein array was used to screen for alterations in the levels of chemokines in foam cells. The protein array revealed a pronounced increase in CCL-2, CCL-3, CCL-4, CCL-5, CCL-7 and fibrinogen levels, and a decrease in CXCL-5 levels in the M1-FC supernatants compared with the macrophages (Fig. 5A and B). However, ELISA confirmed that only the levels of CCL-2 and CCL-4 exhibited a significant increase (Fig. 5C). However, the effects of these cytokines on EndMT are unknown; thus, their effects on EndMT were examined in the present study. CCL-2, CCL-3, CCL-4, CCL-5 and CCL-7 were used to stimulate the HAECs, and the levels of EndMT markers were analyzed. The results presented in Fig. 6 demonstrated a marked increase in EndMT upon CCL-4 stimulation in a time- and concentration dependent manner (Fig. 6A and B), as evidenced by the loss of endothelial marker expression (VE-cadherin) and the increased expression of mesenchymal markers ( $\alpha$-SMA and Vimentin). A weaker effect was observed after CCL-3 and CCL-5 intervention (data not shown). CCL-2 and CCL-7 did not exert any effect on EndMT (data not shown). Additionally, blocking CCL-4 with anti-CCL-4 antibody reversed the abovementioned EndMT-related changes induced by the M1-FC supernatant (Fig. 6C). These data suggest that CCL-4 produced by M1-FCs plays a key role in EndMT.

\section{CCL-4-induced EndMT contributes to endothelial barrier dysfunction. Monocyte adhesion, infiltration and retention in the arteries are key features of atherosclerosis. In this study, to investigate the effect of EndMT on monocyte adhesion, an in vitro adhesion assay was performed to determine the}



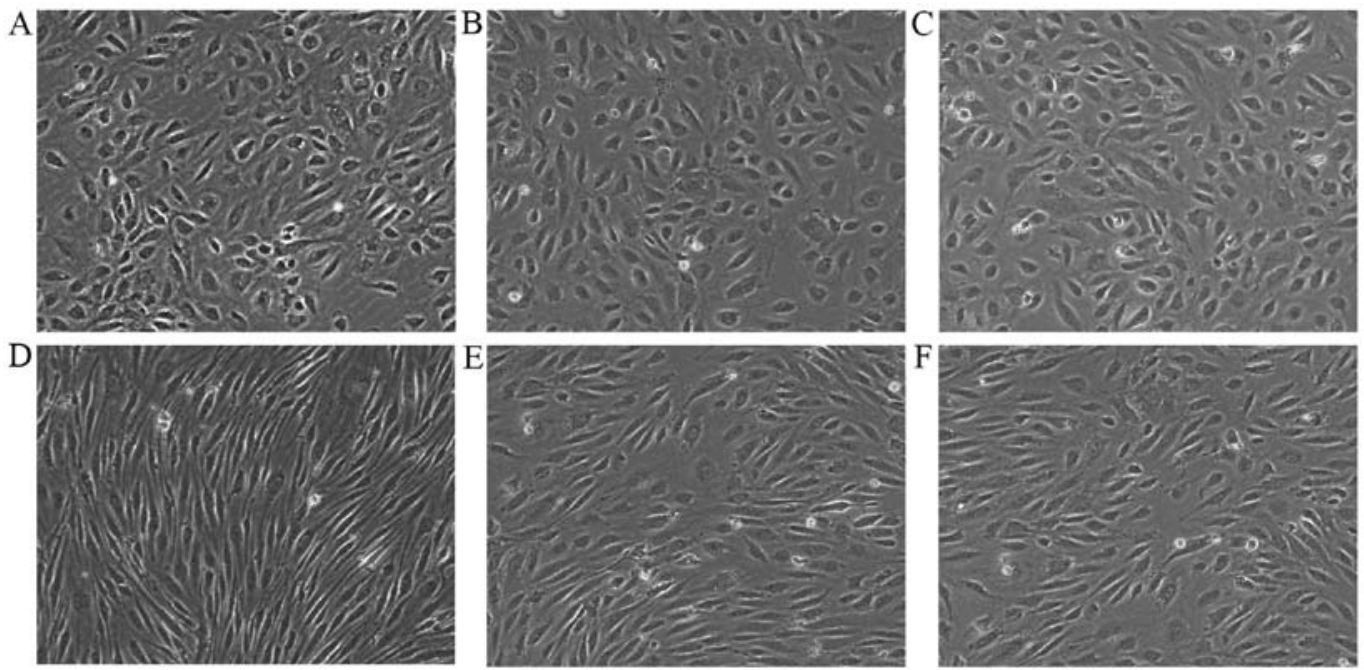

G

$$
\text { Con } \frac{\mathrm{M} 1}{\mathrm{M} \varphi \quad \mathrm{FC}} \frac{\mathrm{M} 2 \mathrm{a}}{\mathrm{M} \varphi \quad \mathrm{FC}} \frac{\mathrm{M} 2 \mathrm{c}}{\mathrm{M} \varphi \quad \mathrm{FC}}
$$

CD31

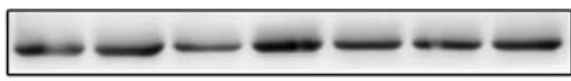

VE-Cadherin

$\alpha-\mathrm{SMA}$

FSP-1

GAPDH

Figure 3. Conditioned medium from M1-FCs stimulates HAECs to undergo EndMT in vitro. HAECs were treated with conditioned medium from different phenotypic macrophages: conditioned medium from (A) M1, (B) M2a and (C) M2c macrophages and (D) M1, (E) M2a and (F) M2c-derived FCs at 1:1 ratio with EBM-2 for 6 days. HAECs treated with conditioned medium from M1-FCs lost the typical cobblestone-like morphology and gained a spindle-like appearance. (G) Western blot analysis of endothelial and mesenchymal cell surface markers demonstrated that HAECs incubated with conditioned medium from M1-FCs underwent EndMT. M1-FCs, M1 macrophage-derived foam cells; Con, control; M $\phi$, macrophage; FC, foam cell; VE-cadherin, vascular endothelial cadherin; $\alpha$-SMA, $\alpha$-smooth muscle actin; FSP-1, fibroblast-specific protein-1; EndMT, endothelial mesenchymal transition.
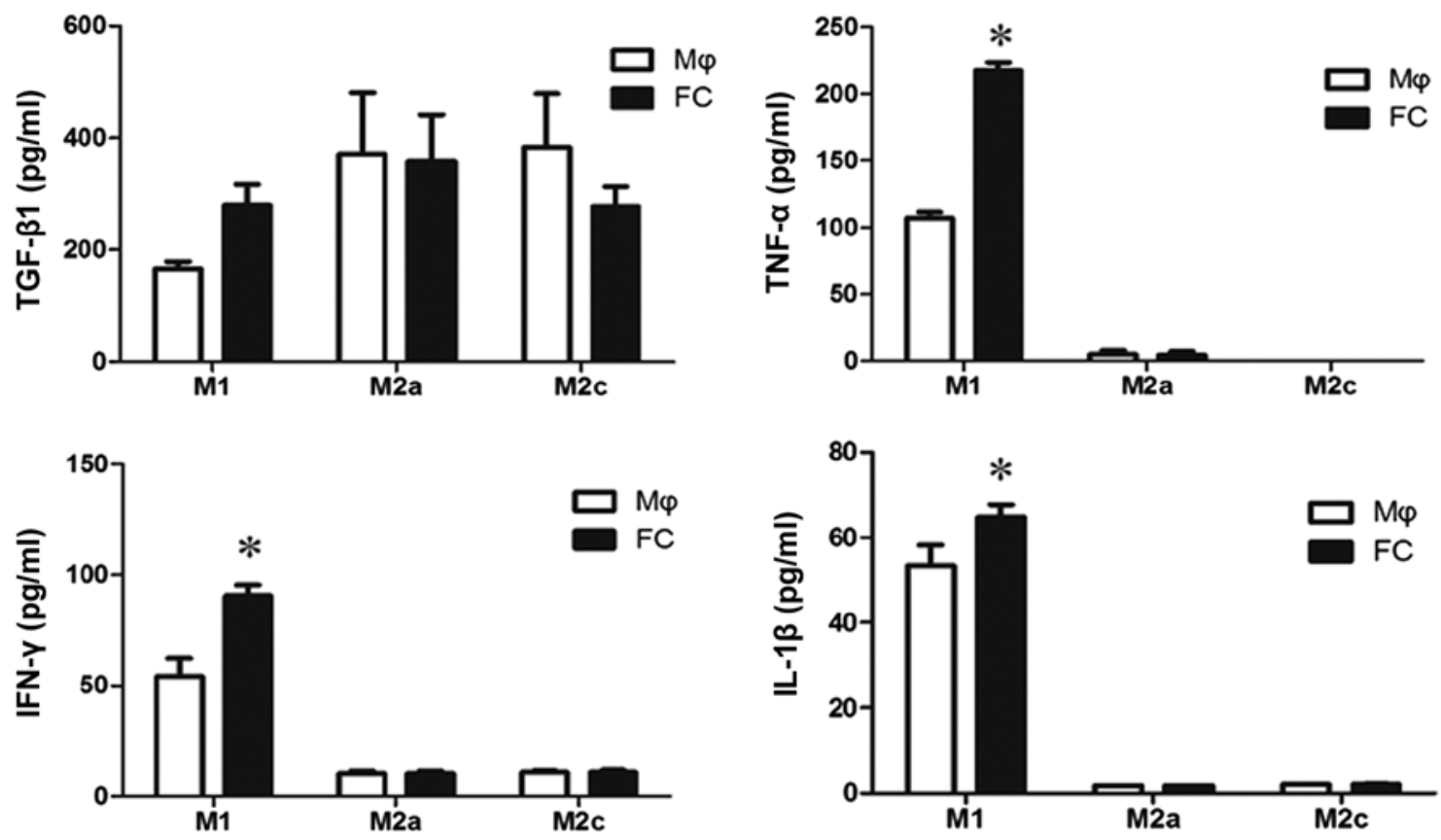

Figure 4. TGF- $\beta 1$, TNF- $\alpha$, IL- $1 \beta$ and IFN- $\gamma$ levels in the supernatants. TGF- $\beta 1$ and cytokine levels in the supernatants of different phenotypic macrophages and foam cells were determined by enzyme-linked immunosorbent assay. Results are presented as the means \pm standard error of 3 independent experiments performed with supernatants of cell cultures from different blood donors. " $\mathrm{P}<0.05$ vs. M1 macrophage, TGF- $\beta 1$, transforming growth factor- $\beta 1$; M $\phi$, macrophage; FC, foam cell; TNF- $\alpha$, transforming growth factor- $\alpha$; IL- $1 \beta$, interleukin- $1 \beta$; IFN- $\gamma$, interferon- $\gamma$. 


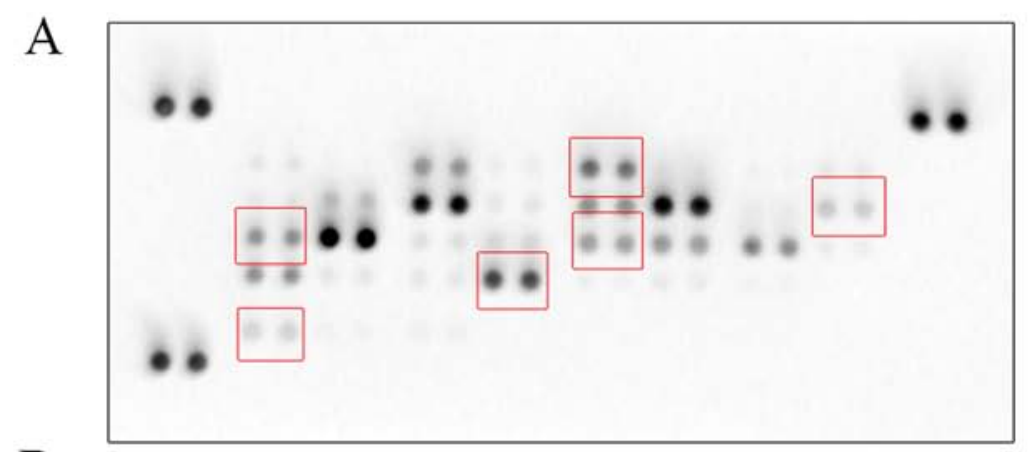

B
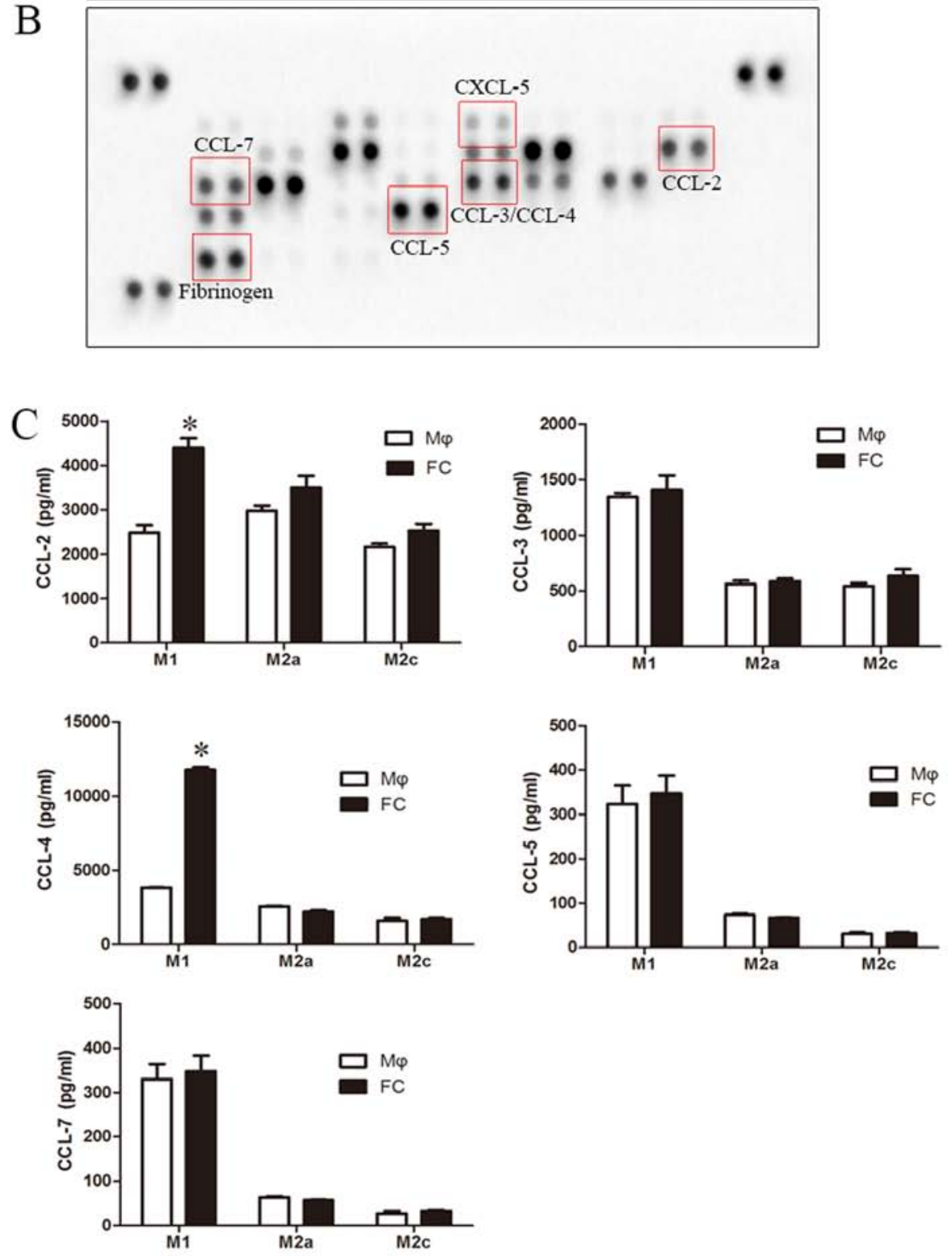

Figure 5. Secretion of chemokines in different phenotypic macrophages and FCs. Conditioned media from (A) M1 macrophages and (B) FC were evaluated using a human chemokine array. (C) CCL-2, CCL-3, CCL-4, CCL-5 and CCL-7 levels in the supernatants were determined by enzyme-linked immunosorbent assay. Results are presented as the means \pm standard error of 3 independent experiments performed with supernatants of cell cultures from different blood donors. "P<0.05 vs. M1 macrophage. CCL, C-C motif chemokine ligand; CXCL-5, C-X-C motif chemokine ligand-5; M $\phi$, macrophage; FC, foam cell.

adhesion of calcein-AM-stained THP-1 cells to HAECs. We found that a small number of THP-1 monocytes adhered to quiescent HAECs, but many more THP-1 monocytes adhered to the CCL-4-treated HAECs (Fig. 7A and B). Western blot analysis revealed the enhanced expression of VCAM-1 in the HAECs stimulated with CCL-4 (Fig. 7C). These results suggest that EndMT induced by CCL-4 contributes to inflammatory cell adhesion to the vascular endothelium.

Additionally, the loss of endothelial barrier integrity contributes to the activation and formation of arterial lesions. Thus, endothelial permeability was assessed using FITC-dextran. In the cells undergoing CCL-4-induced EndMT, a >2-fold 


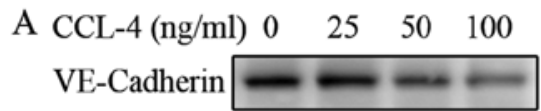

Vimentin

$\alpha-$ SMA

GAPDH
B CCL-4 (days)
VE-Cadherin

Vimentin

$\alpha-$ SMA

GAPDH
$\mathrm{C}_{\mathrm{CD} 31}$

Vimentin

GAPDH

M1-FC

anti-CCL-4

IgG

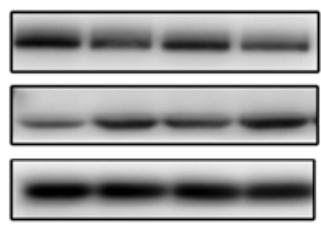

- $+\quad+\quad+$

- $\quad$ - + -

- $\quad-\quad-4$

Figure 6. CCL-4 induces EndMT in a concentration- and time-dependent manner. (A) HAECs were cultured in medium containing 0, 25, 50 or 100 ng/ml CCL-4 for 6 days, and (B) HAECs were cultured in medium containing $100 \mathrm{ng} / \mathrm{ml} \mathrm{CCL-} 4$ for 2, 4 or 6 days; the levels of VE-cadherin, vimentin and $\alpha$-SMA were determined by western blot analysis (C) EndMT induced by conditioned medium of M1-FCs was neutralized by human anti-CCL-4 antibody. Human CCL-4 neutralizing antibody $(10 \mu \mathrm{g} / \mathrm{ml})$ or isotype control were incubated at $37^{\circ} \mathrm{C}$ with conditioned medium for $1 \mathrm{~h}$ before addition to $\mathrm{HAECs}$. EndMT, endothelial mesenchymal transition; HAEC, human aortic endothelial cell; CCL-4, C-C motif chemokine ligand-4; VE-cadherin, vascular endothelial cadherin; $\alpha$-SMA, $\alpha$-smooth muscle actin; M1-FC, M1 macrophage-derived foam cell; IgG, immunoglobulin G.
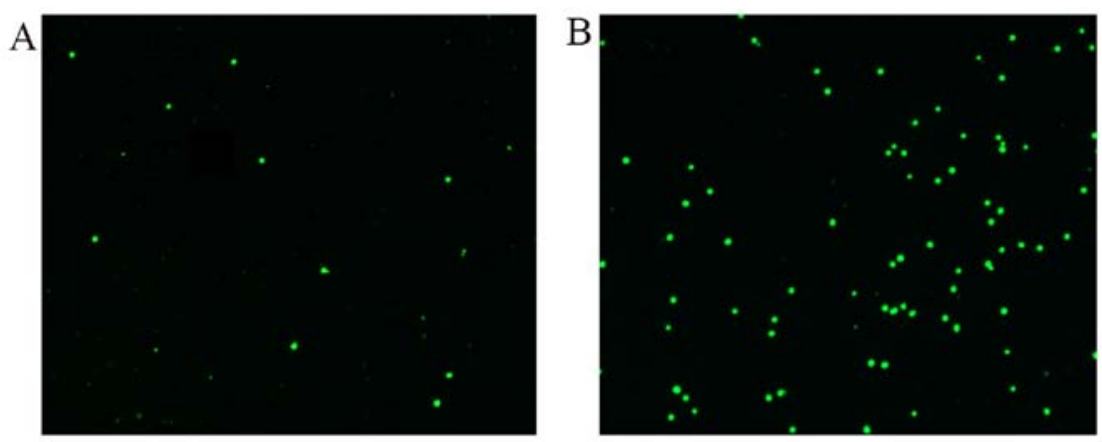

$\mathrm{C}$
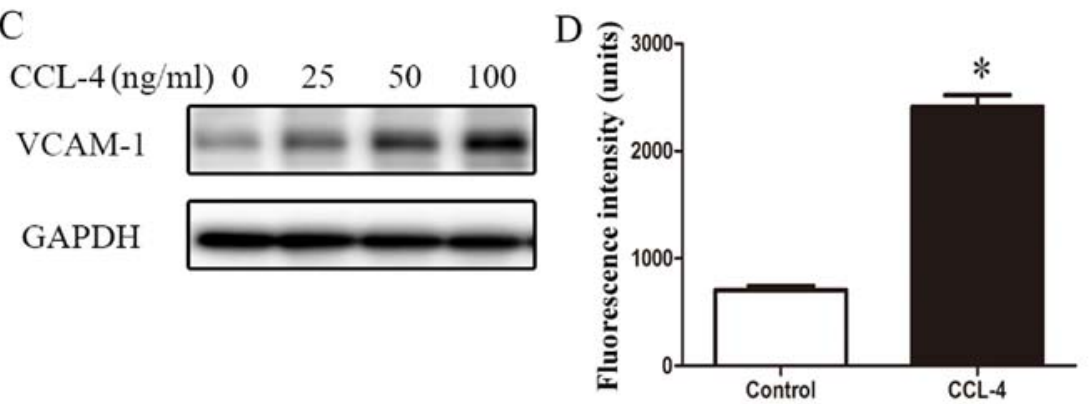

Figure 7. CCL-4-induced EndMT contributes to endothelial barrier dysfunction. HAECs were pre-treated (A) without or (B) with 100 ng/ml CCL-4 for 6 days and then co-cultured with calcein-AM-labeled THP-1 monocytes for $1 \mathrm{~h}$. Micrographs ( 3 independent experiments) were obtained using fluorescence microscopy with a fluorescein blue filter. Magnification, $x 40$. (C) Western blot analysis demonstrating the effect of CCL-4 at different concentration on the expression levels of VCAM-1 in HAECs. (D) Permeability of HAECs was examined by the amount of fluorescein isothiocyanate-dextran to permeate the HAECs monolayer. Values are presented as the means \pm standard error from 3 experiments. ${ }^{*} \mathrm{P}<0.05$ vs. control. HAEC, human aortic endothelial cells; CCL-4, C-C motif chemokine ligand-4; VCAM-1, vascular cell adhesion molecule-1; EndMT, endothelial mesenchymal transition.

increase in endothelial leakage compared with the untreated cells in monolayer was observed (Fig. 7D).

$C-C$ motif chemokine receptor-5 (CCR-5) and TGF- $\beta$ are involved in $C C L$-4-induced EndMT. The mechanisms through which CCL-4 induces EndMT are not clear. Currently, CCR-5 is the unique known receptor of CCL-4. Therefore, in this study, we investigated whether CCR-5 mediates CCL-4induced EndMT. Maraviroc is a widely used CCR-5 antagonist. In this experiment, CD31 expression was restored and the vimentin level was reduced in the HAECs treated with CCL-4 and maraviroc compared with the cells stimulated only with CCL-4, which indicates that CCR-5 is involved in mediating CCL-4-induced EndMT (Fig. 8A).
The downstream mechanisms of CCR-5 in the process of EndMT are still unclear. It was previously reported that CCR-5 may modify the expression of TGF- $\beta$, a key EndMT protein, in endothelial progenitor cells (38). Therefore, the effect of the CCL-4/CCR-5 axis on TGF- $\beta$ expression was investigated in this study. We observed that TGF- $\beta$ expression was markedly increased in the HAECs stimulated with CCL-4 compared with the untreated HAECs; however, this effect was abolished by pre-treatment with the CCR-5 antagonist, maraviroc (Fig. 8B). Notably, the knockdown of TGF- $\beta$ expression in the HAECs inhibited the EndMT induced by CCL-4, as indicated by the restored expression of CD31 and the decreased expression of vimentin following TGF- $\beta$ knockdown and CCL- 4 stimulation (Fig. 8C). These data indicated that CCL-4 promoted 


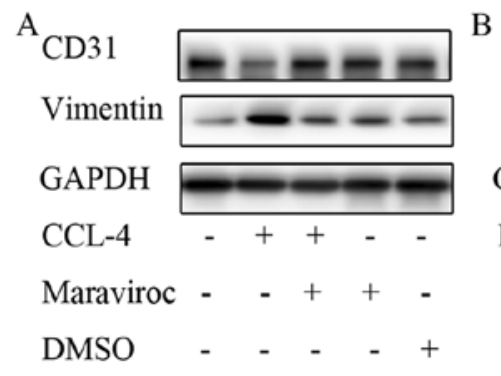

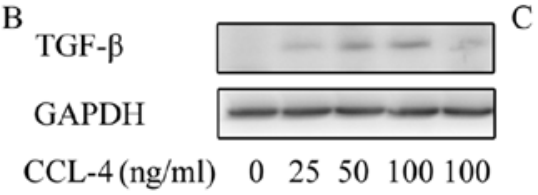

Maraviroc

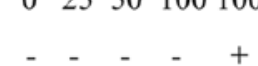

CD31
Vimentin
GAPDH
CCL-4

Adv-shRNA-TGF- $\beta$

Adv-GFP

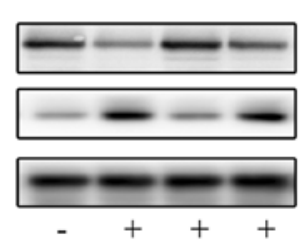

$-+++$

Figure 8. CCL-4 increases TGF- $\beta$ levels via CCR-5. (A) Maraviroc, a C-C motif chemokine receptor-5 inhibitor, restored CD31 expression and reduced vimentin level following CCL-4-induced EndMT. (B) TGF- $\beta$ expression was increased in HAECs by CCL-4 in a concentration-dependent manner, and the effect was blocked by maraviroc. (C) Knockdown of TGF- $\beta$ expression in HAECs inhibited endothelial mesenchymal transition induced by CCL-4, as indicated by the reduced expression of vimentin and the restored expression of CD31. CCL-4, C-C motif chemokine ligand-4; EndMT, endothelial mesenchymal transition; DMSO, dimethyl sulfoxide; HAEC, human aortic endothelial cell; TGF- $\beta$, transforming growth factor- $\beta$; shRNA, short hairpin RNA; GFP, green fluorescent protein.

TGF- $\beta$ expression via CCR-5, which induced EndMT in HAECs. Thus, even though TGF- $\beta$ expression exhibited no significant increase inthe macrophages differentiating into foam cells, it was upregulated by CCL-4 in the endothelium and promoted EndMT.

\section{Discussion}

Endothelial dysfunction is a key factor that triggers and exacerbates the formation of atherosclerotic lesions. The present study demonstrated that the endothelial space was much wider and EndMT occurred in the intima of human aortic atherosclerotic plaques, however, it was absent in the normal aorta, which indicated that the endothelial barrier was destroyed in the atherosclerotic artery. We also observed that endothelial barrier dysfunction associated with EndMT contributed to monocyte adhesion to the endothelium and infiltration into the subendothelium and a pro-inflammatory cell phenotype. Further experiments revealed that EndMT was induced by chemokine CCL-4 in a paracrine manner in M1-FCs in vitro by increasing TGF- $\beta$ expression.

EndMT may be a repair response or adaptation to pathological stimulus, and contributes to the onset and progression of vascular pathology. It has recently been confirmed that EndMT is common during atherosclerosis and drives the progression of atherosclerosis by increasing the deposition of fibronectin and adhesion molecules (16) and, altering the collagen-matrix metalloproteinase balance (17). During the process of EndMT, intimal endothelial cells lose their integrity followed by increased endothelial barrier permeability and enhanced adhesion molecule expression accompanied by increased monocyte adhesion (7). Despite above-mentioned effects of EndMT on atherosclerosis, the mechanisms through which EndMT mediates the process of atherogenesis are largely unknown. The infiltration of various inflammatory cells is an early and crucial process during the development of atherosclerotic lesions. Inside the vascular wall, inflammatory cells differentiate into macrophages and ingest ox-LDL to form lipid-rich foam cells, which is the pivotal pathological change of atherosclerosis. In the present study, M1-FCs were demonstrated to secrete CCL-4 and promote EndMT, which additionally increased endothelial permeability and exacerbated monocyte infiltration, thus, forming a positive loop to promote the development of atherosclerotic lesions. To the best of our knowledge, the present study is the first to report that macrophages induce EndMT, whereas other studies have demonstrated that EMT can be induced by macrophages $(34,35)$.

Previous studies have demonstrated that a direct increase in TGF- $\beta$ expression is involved in EMT. Additionally, the majority of studies have reported that EMT is induced by M2 macrophages $(35,39)$; however, EndMT was not induced by M2 macrophages in the present study. The most plausible explanation for these differences between the effects of M2 macrophages on EMT and EndMT may be that different cell types exert diverse effects. However, M2 macrophages may promote angiogenesis in a paracrine manner $(40,41)$; as is already known, angiogenesis plays an important role in the development of atherosclerotic and plaque instability (42-44). Theoretically speaking, M2 macrophages should be proatherogenic due to their pro-angiogenic effects. However, the emerging understanding of macrophage subsets and their functions in atherosclerotic plaque has led to the consensus that M1 macrophages are pro-atherogenic, while M2 macrophages may promote plaque stability $(27,28,45)$, primarily though their tissue repair and anti-inflammatory properties. Additionally, our previous study demonstrated that EndMT damaged endothelial tube formation capacity in an in vitro angiogenesis assay (46), which is consistent with our present results.

The present study demonstrated that CCL-4 was crucial for M1-FC-induced EndMT, and to the best of our knowledge, this is the first report to investigate the association between EndMT/EMT and CCL-4. CCL-4 has been previously reported to be associated with the development of atherosclerosis. Population studies have demonstrated that increased CCL-4 levels are associated with a poor prognosis for coronary heart disease (47-49). Mechanistic analysis has indicated that CCL-4 is increased in atherosclerotic plaques, and reducing its expression or inhibiting it with a CCR-5 antagonist can attenuate the development of atherosclerosis (50). Classically, CCL-4 is regarded as a pro-inflammatory cytokine and mediates the inflammatory cascade, promoting atherosclerotic lesion formation. The present study provided novel insight into EndMT and the subsequent inflammatory cell infiltration and adhesion, explaining the adverse effects of CCL-4 on atherosclerosis. Additionally, our study demonstrated that the malignant effects of CCL-4 were at least partially induced through CCR-5, the only recognized receptor of CCL-4. As expected, CCR-5 has 
been reported to be involved in atherosclerosis. Increased monocyte CCR-5 expression is associated with atherosclerosis, and statins therapy has been demonstrated to reduce CCR-5 concentrations $(51,52)$. Furthermore, CCR-5 expression in monocytes has been demonstrated to be important for migration during the development of atherosclerosis (53) and the CCR5 antagonist, maraviroc, has been shown to be effective in limiting plaque progression in different atherosclerosis animal models (54). The present study also demonstrated that monocytes were prone to adhere to the endothelial monolayer following CCL-4 treatment, which explains the findings from the aspect of a paracrine signaling mechanism and supports that maraviroc, a drug used widely in clinical practice, may be a novel potential treatment for atherosclerosis.

Certain limitations of the present study should be noted. Firstly, the protein array was performed to measure chemotactic cytokine family members; thus, even though classical inflammatory cytokines promote EndMT, numerous cytokines that are not part of this group were not examined. Additionally, the mechanism through which CCL-4/CCR5 promotes TGF- $\beta$ was not determined, and there is currently no reported evidence regarding this regulatory mechanism, at least to the best of our knowledge.

Despite limitations, the present study demonstrated that EndMT is involved in endothelial barrier dysfunction and is associated with plaque development. This study investigated the molecular mechanisms that mediate EndMT and elucidated a potential paracrine mechanism involving the interaction between macrophages and endothelial function, which may be beneficial for developing novel treatments for atherosclerosis via targeting the CCL-4/CCR5 axis.

\section{Acknowledgements}

This study was financially supported by grants from the National Natural Science Foundation of China (nos. 91439125, 81270212, 81570213, 81100101, 81570329 and 81500223), the Guangdong Province Natural Science Fund (nos. S2013010014011 and 2015A030310059) and the Science and Technology Program of Guangzhou (no. 2014Y2-00118).

\section{References}

1. Herrington W, Lacey B, Sherliker P, Armitage J and Lewington S: Epidemiology of atherosclerosis and the potential to reduce the global burden of atherothrombotic disease. Circ Res 118: 535-546, 2016.

2. Schulte D, Küppers V, Dartsch N, Broermann A, Li H, Zarbock A, Kamenyeva O, Kiefer F, Khandoga A, Massberg S, et al: Stabilizing the VE-cadherin-catenin complex blocks leukocyte extravasation and vascular permeability. EMBO J 30: 4157-4170, 2011.

3. Giannotta M, Trani M and Dejana E: VE-cadherin and endothelial adherens junctions: Active guardians of vascular integrity. Dev Cell 26: 441-454, 2013.

4. Steffensen LB, Mortensen MB, Kjolby M, Hagensen MK, Oxvig $\mathrm{C}$ and Bentzon JF: Disturbed laminar blood flow vastly augments lipoprotein retention in the artery wall: A key mechanism distinguishing susceptible from resistant sites. Arterioscler Thromb Vasc Biol 35: 1928-1935, 2015.

5. Monette JS, Hutchins PM, Ronsein GE, Wimberger J, Irwin AD, Tang C, Sara JD, Shao B, Vaisar T, Lerman A, et al: Patients with coronary endothelial dysfunction have impaired cholesterol efflux capacity and reduced HDL particle concentration. Circ Res 119: 83-90, 2016.
6. Zeisberg EM, Tarnavski O, Zeisberg M, Dorfman AL, McMullen JR, Gustafsson E, Chandraker A, Yuan X, Pu WT, Roberts $\mathrm{AB}$, et al: Endothelial-to-mesenchymal transition contributes to cardiac fibrosis. Nat Med 13: 952-961, 2007.

7. Good RB, Gilbane AJ, Trinder SL, Denton CP, Coghlan G, Abraham DJ and Holmes AM: Endothelial to mesenchymal transition contributes to endothelial dysfunction in pulmonary arterial hypertension. Am J Pathol 185: 1850-1858, 2015.

8. Yan Z, Wang ZG, Segev N, Hu S, Minshall RD, Dull RO, Zhang M, Malik AB and Hu G: Rab1la mediates vascular endothelial-cadherin recycling and controls endothelial barrier function. Arterioscler Thromb Vasc Biol 36: 339-349, 2016.

9. Zeisberg EM, Potenta SE, Sugimoto H, Zeisberg M and Kalluri R: Fibroblasts in kidney fibrosis emerge via endothelial-to-mesenchymal transition. J Am Soc Nephrol 19: 2282-2287, 2008.

10. Ranchoux B, Antigny F, Rucker-Martin C, Hautefort A, Péchoux C, Bogaard HJ, Dorfmüller P, Remy S, Lecerf F, Planté $\mathrm{S}$, et al: Endothelial-to-mesenchymal transition in pulmonary hypertension. Circulation 131: 1006-1018, 2015.

11. Choi SH, Hong ZY, Nam JK, Lee HJ, Jang J, Yoo RJ, Lee YJ, Lee CY, Kim KH, Park S, et al: A hypoxia-induced vascular endothelial-to-mesenchymal transition in development of radiation-induced pulmonary fibrosis. Clin Cancer Res 21: 3716-3726, 2015

12. Yung LM, Sánchez-Duffhues G, Ten Dijke P and Yu PB: Bone morphogenetic protein 6 and oxidized low-density lipoprotein synergistically recruit osteogenic differentiation in endothelial cells. Cardiovasc Res 108: 278-287, 2015.

13. Xu X, Friehs I, Zhong Hu T, Melnychenko I, Tampe B, Alnour F, Iascone M, Kalluri R, Zeisberg M, Del Nido PJ, et al: Endocardial fibroelastosis is caused by aberrant endothelial to mesenchymal transition. Circ Res 116: 857-866, 2015.

14. Kim M, Choi SH, Jin YB, Lee HJ, Ji YH, Kim J, Lee YS and Lee YJ: The effect of oxidized low-density lipoprotein (ox-LDL) on radiation-induced endothelial-to-mesenchymal transition. Int J Radiat Biol 89: 356-363, 2013.

15. Moonen JR, Lee ES, Schmidt M, Maleszewska M, Koerts JA, Brouwer LA, van Kooten TG, van Luyn MJ, Zeebregts CJ, Krenning G, et al: Endothelial-to-mesenchymal transition contributes to fibro-proliferative vascular disease and is modulated by fluid shear stress. Cardiovasc Res 108: 377-386, 2015.

16. Chen PY, Qin L, Baeyens N,LiG, Afolabi T,Budatha M, Tellides G, Schwartz MA and Simons M: Endothelial-to-mesenchymal transition drives atherosclerosis progression. J Clin Invest 125: 4514-4528, 2015.

17. Evrard SM, Lecce L, Michelis KC, Nomura-Kitabayashi A, Pandey G, Purushothaman KR, d'Escamard V, Li JR, Hadri L, Fujitani K, et al: Endothelial to mesenchymal transition is common in atherosclerotic lesions and is associated with plaque instability. Nat Commun 7: 11853, 2016.

18. Badimon L, Storey RF and Vilahur G: Update on lipids, inflammation and atherothrombosis. Thromb Haemost 105 (Suppl 1): S34-S42, 2011.

19. Libby P: Inflammation in atherosclerosis. Arterioscler Thromb Vasc Biol 32: 2045-2051, 2012.

20. Webb NR and Moore KJ: Macrophage-derived foam cells in atherosclerosis: lessons from murine models and implications for therapy. Curr Drug Targets 8: 1249-1263, 2007.

21. Randolph GJ: Mechanisms that regulate macrophage burden in atherosclerosis. Circ Res 114: 1757-1771, 2014.

22. Hung Y, Hong M and Huang GS: Cholesterol loading augments oxidative stress in macrophages. FEBS Lett 580: 849-861, 2006.

23. Mantovani A, Sica A, Sozzani S, Allavena P, Vecchi A and Locati M: The chemokine system in diverse forms of macrophage activation and polarization. Trends Immunol 25: 677-686, 2004.

24. Chinetti-Gbaguidi G, Colin S and Staels B: Macrophage subsets in atherosclerosis. Nat Rev Cardiol 12: 10-17, 2015.

25. Leitinger N and Schulman IG: Phenotypic polarization of macrophages in atherosclerosis. Arterioscler Thromb Vasc Biol 33: $1120-1126,2013$

26. Fang S, Xu Y, Zhang Y, Tian J, Li J, Li Z, He Z, Chai R, Liu F, Zhang $\mathrm{T}$, et al: Irgm1 promotes M1 but not M2 macrophage polarization in atherosclerosis pathogenesis and development. Atherosclerosis 251: 282-290, 2016.

27. McAlpine CS, Huang A, Emdin A, Banko NS, Beriault DR, Shi Y and Werstuck GH: Deletion of myeloid GSK $3 \alpha$ attenuates atherosclerosis and promotes an M2 macrophage phenotype. Arterioscler Thromb Vasc Biol 35: 1113-1122, 2015. 
28. Yin K, You Y, Swier V, Tang L, Radwan MM, Pandya AN, Agrawal DK and Vitamin D: Vitamin D protects against atherosclerosis via regulation of cholesterol efflux and macrophage polarization in hypercholesterolemic swine. Arterioscler Thromb Vasc Biol 35: 2432-2442, 2015.

29. Zhang Y, Choksi S, Chen K, Pobezinskaya Y, Linnoila I and Liu ZG: ROS play a critical role in the differentiation of alternatively activated macrophages and the occurrence of tumor-associated macrophages. Cell Res 23: 898-914, 2013.

30. Bai J, Adriani G, Dang TM, Tu TY, Penny HX, Wong SC, Kamm RD and Thiery JP: Contact-dependent carcinoma aggregate dispersion by M2a macrophages via ICAM- 1 and $\beta 2$ integrin interactions. Oncotarget 6: 25295-25307, 2015.

31. Mai J, Qiu Q, Lin YQ, Luo NS, Zhang HF, Wen ZZ, Wang JF and YangXin C: Angiotensin II-derived reactive oxygen species promote angiogenesis in human late endothelial progenitor cells through heme oxygenase-1 via ERK1/2 and AKT/PI3K pathways. Inflammation 37: 858-870, 2014.

32. Kim M, Neinast MD, Frank AP, Sun K, Park J, Zehr JA, Vishvanath L, Morselli E, Amelotte M, Palmer BF, et al: ERo upregulates Phd3 to ameliorate HIF-1 induced fibrosis and inflammation in adipose tissue. Mol Metab 3: 642-651, 2014.

33. Mai J, Hu Q, Xie Y, Su S, Qiu Q, Yuan W, Yang Y, Song E, Chen Y and Wang J: Dyssynchronous pacing triggers endothelial-mesenchymal transition through heterogeneity of mechanical stretch in a canine model. Circ J 79: 201-209, 2015.

34. Su S, Liu Q, Chen J, Chen J, Chen F, He C, Huang D, Wu W, Lin L, Huang W, et al: A positive feedback loop between mesenchymal-like cancer cells and macrophages is essential to breast cancer metastasis. Cancer Cell 25: 605-620, 2014.

35. Yeung OW, Lo CM, Ling CC, Qi X, Geng W, Li CX, Ng KT, Forbes SJ, Guan XY, Poon RT, et al: Alternatively activated (M2) macrophages promote tumour growth and invasiveness in hepatocellular carcinoma. J Hepatol 62: 607-616, 2015.

36. Zernecke A and Weber C: Chemokines in atherosclerosis: proceedings resumed. Arterioscler Thromb Vasc Biol 34: 742-750, 2014.

37. Drechsler M, Duchene J and Soehnlein O: Chemokines control mobilization, recruitment, and fate of monocytes in atherosclerosis. Arterioscler Thromb Vasc Biol 35: 1050-1055, 2015.

38. Ishida Y, Kimura A, Kuninaka Y, Inui M, Matsushima K, Mukaida N and Kondo T. Pivotal role of the CCL5/CCR5 interaction for recruitment of endothelial progenitor cells in mouse wound healing. J Clin Invest 122: 711-721, 2012.

39. Sugg KB, Lubardic J, Gumucio JP and Mendias CL: Changes in macrophage phenotype and induction of epithelial-to-mesenchymal transition genes following acute Achilles tenotomy and repair. J Orthop Res 32: 944-951, 2014.

40. Tripathi C, Tewari BN, Kanchan RK, Baghel KS, Nautiyal N, Shrivastava R, Kaur H, Bhatt ML and Bhadauria S: Macrophages are recruited to hypoxic tumor areas and acquire a proangiogenic M2-polarized phenotype via hypoxic cancer cell derived cytokines Oncostatin M and Eotaxin. Oncotarget 5: $5350-5368,2014$

41. Jetten N, Verbruggen S, Gijbels MJ, Post MJ, De Winther MP and Donners MM: Anti-inflammatory M2, but not pro-inflammatory M1 macrophages promote angiogenesis in vivo. Angiogenesis 17: 109-118, 2014

42. Virmani R, Kolodgie FD, Burke AP, Finn AV, Gold HK, Tulenko TN, Wrenn SP and Narula J: Atherosclerotic plaque progression and vulnerability to rupture: Angiogenesis as a source of intraplaque hemorrhage. Arterioscler Thromb Vasc Biol 25: 2054-2061, 2005.
43. Hutter R, Speidl WS, Valdiviezo C, Sauter B, Corti R, Fuster V and Badimon JJ: Macrophages transmit potent proangiogenic effects of oxLDL in vitro and in vivo involving HIF-1 $\alpha$ activation: A novel aspect of angiogenesis in atherosclerosis. J Cardiovasc Transl Res 6: 558-569, 2013.

44. Giannarelli C, Alique M, Rodriguez DT, Yang DK, Jeong D, Calcagno C, Hutter R, Millon A, Kovacic JC, Weber T, et al: Alternatively spliced tissue factor promotes plaque angiogenesis through the activation of hypoxia-inducible factor- $1 \alpha$ and vascular endothelial growth factor signaling. Circulation 130 : 1274-1286, 2014

45. Ouimet M, Ediriweera HN, Gundra UM, Sheedy FJ, Ramkhelawon B, Hutchison SB, Rinehold K, van Solingen C, Fullerton MD, Cecchini K, et al: MicroRNA-33-dependent regulation of macrophage metabolism directs immune cell polarization in atherosclerosis. J Clin Invest 125: 4334-4348, 2015.

46. Ying R, Wang XQ, Yang Y, Gu ZJ, Mai JT, Qiu Q, Chen YX and Wang JF: Hydrogen sulfide suppresses endoplasmic reticulum stress-induced endothelial-to-mesenchymal transition through Src pathway. Life Sci 144: 208-217, 2016.

47. Xu F, Lv S, Chen Y, Song X, Jin Z, Yuan F, Zhou Y and Li H: Macrophage inflammatory protein- $1 \beta$ and fibrinogen are synergistic predictive markers of prognosis of intermediate coronary artery lesions. Cardiology 121: 12-19, 2012.

48. Edsfeldt A, Grufman H, Asciutto G, Nitulescu M, Persson A, Nilsson M, Nilsson $\mathbf{J}$ and Gonçalves I: Circulating cytokines reflect the expression of pro-inflammatory cytokines in atherosclerotic plaques. Atherosclerosis 241: 443-449, 2015.

49. Gentili A, Zaibi MS, Alomar SY, De Vuono S, Ricci MA, Alaeddin A, Siepi D, Boni M, Vaudo G, Trayhurn P, et al: Circulating levels of the adipokines monocyte chemotactic protein-4 (MCP-4), macrophage inflammatory protein- $1 \beta$ (MIP-1 $\beta$ ), and eotaxin-3 in severe obesity and following bariatric surgery. Horm Metab Res 48: 847-853, 2016.

50. Vistnes M: Macrophage inflammatory protein-1ß: A novel prognostic biomarker in atherosclerosis? Cardiology 121: 149-151, 2012.

51. Salic K, Morrison MC, Verschuren L, Wielinga PY, Wu L, Kleemann R, Gjorstrup P and Kooistra T: Resolvin E1 attenuates atherosclerosis in absence of cholesterol-lowering effects and on top of atorvastatin. Atherosclerosis 250: 158-165, 2016.

52. Hsu DC, Ma YF, Hur S, Li D, Rupert A, Scherzer R, Kalapus SC, Deeks S, Sereti I and Hsue PY: Plasma IL-6 levels are independently associated with atherosclerosis and mortality in HIV-infected individuals on suppressive antiretroviral therapy. AIDS 30: 2065-2074, 2016.

53. Herbin O, Regelmann AG, Ramkhelawon B, Weinstein EG, Moore KJ and Alexandropoulos K: Monocyte adhesion and plaque recruitment during atherosclerosis development is regulated by the adapter protein Chat-H/SHEP1. Arterioscler Thromb Vasc Biol 36: 1791-1801, 2016.

54. Cipriani S, Francisci D, Mencarelli A, Renga B, Schiaroli E, D'Amore C, Baldelli F and Fiorucci S: Efficacy of the CCR5 antagonist maraviroc in reducing early, ritonavir-induced atherogenesis and advanced plaque progression in mice. Circulation 127: 2114-2124, 2013. 